\title{
Notas serenas. Las hermanas Cossettini y la enseñanza de la música en su experiencia educativa en Rosario, Argentina
}

Serene Notes: The Cossettini sisters and music teaching in their educational experience in Rosario, Argentina

\section{Consejo Nacional de Investigaciones Cientificas y Técnicas. \\ Universidad Nacional de Rosario, Argentina \\ 7acequias@gmail.com \\ fernandez@ishir-conicet.gov.ar}

Micaela Yunis

Universidad Nacional de Rosario, Argentina

micaelayunis@hotmail.com

\section{Resumen}

\begin{abstract}
Este artículo apunta a demostrar la singularidad y trascendencia del caso de la Escuela Experimental Gabriel Carrasco, de Rosario, Argentina, con relación a la enseñanza y difusión musical propiciada por las hermanas Cossettini en dicha institución entre 1935-1950. Para destacar la peculiaridad de esta experiencia, aun dentro del propio escolanovismo vernáculo, esta investigación está centrada en dos grandes temas: la gran preocupación de las hermanas Cossettini por incorporar la música como elemento central de su propuesta curricular a través de sus Conciertos fonoeléctricos y las Misiones Culturales (Coro de Pájaros), y el diálogo internacional con referentes del mundo de la educación musical para transformar la enseñanza, y difundir e intercambiar resultados.
\end{abstract}

Palabras clave: música, educación, Cossettini, Rosario, escolanovismo. 
This article aims to demonstrate the uniqueness and significance of the case of the Gabriel Carrasco Experimental School in Rosario, as regards the teaching and dissemination of music, driven at this institution by the Cossettini sisters between 1935-1950. To highlight the singularity of this experience, though still within the local progressive school movement, this research is focused on two main topics: one, the great concern of the sisters Cossettini to incorporate music as a central element of their curricular proposal through their so-called "phono-electric" concerts and "cultural missions"; and two, the international dialog with exponents of the music education world to transform education and to spread and exchange results.

Keywords: Music, Education, Cossettini, Rosario, Progressive School Movement

\section{Introducción}

La música es una manifestación que acompaña a los seres humanos casi desde sus primeros momentos de vida y desde la más remota antigüedad. Tal es la naturalidad con la que se nos presenta, que se ha vuelto un lugar común definirla muchas veces casi como un lenguaje con lógica propia y de significación universal.

Asimismo, existe el convencimiento generalizado de que la presencia del fenómeno musical durante la infancia es de vital importancia no sólo para la adquisición de las destrezas específicas de dicho arte, sino también para el desarrollo integral del niño como individuo, dado que la experiencia sensorial que proporciona enriquece su vida y favorece su equilibrio emocional, psicológico y social; por ello, nos resulta fácil aceptar esta premisa ahora, que el factor psicológico del niño cumple un rol preponderante en todos los programas educativos y proyectos de didáctica escolar. Esta idea, instalada en el "sentido común" escolar desde hace varias décadas dentro del sistema educativo argentino, tuvo un contexto de transformación de la mano de las experiencias escolanovistas de las primeras décadas del siglo XX.

El lugar que ha se le ha dado a la música en la escuela no ha sido siempre el mismo; tampoco así el objetivo por el cual se le ha permitido ingresar en el aula. Según Jorquera podemos descubrir que la inserción de la educación musical en ámbitos escolares se dio por primera vez en los colegios de la Inglaterra victoriana, en respuesta a la necesidad de desarrollar en los alumnos aptitudes lectoescritoras para que pudieran insertarse en los coros congregacionales que acompañaban los servicios religiosos (Jorquera, 2004: 20). Por otro lado, si pensamos en el sistema educativo argentino luego de implantada la Ley 1420, y consideramos algunos de los debates en torno de la enseñanza de la música en la escuela a través de las publicaciones educativas de la época, vemos que "música", como asignatura, 
es concebida en este contexto como el espacio en el que a los niños se les hace aprender himnos patrios y cantos para actos y celebraciones concretas, junto con las nociones básicas de solfeo para entonarlos.

El escolanovismo con relación a la enseñanza marcó un punto de inflexión en el horizonte educativo de Argentina. ${ }^{1}$ El caso excepcional de la escuela experimental Gabriel Carrasco, de la ciudad de Rosario, Argentina, en la que las hermanas Olga y Leticia Cossettini desarrollaron su experiencia pedagógica entre 1935 y 1950, es una muestra de tal praxis. Atravesada por los ideales de la "Escuela Serena", dicha experiencia generaba un ámbito escolar en el que se privilegiaba la enseñanza a partir del hecho artístico. La música, por cierto, no era ajena en las aulas y en los recreos de la escuela Carrasco. Diversas fuentes ${ }^{3}$ describen un espacio escolar lleno de música, color y juego. Lo que significaba que, más allá del trabajo en el espacio curricular, la música formaba parte de las actividades cotidianas de la institución al involucrar docentes, alumnos, visitantes y vecinos, tanto durante el trabajo áulico, como en los recreos y en las excursiones por el barrio y los alrededores.

Violeta Gainza, al presentarnos un recorrido histórico centrado en los métodos pedagógicos de la educación musical, señala la transformación que supuso la revolución educativa de la Escuela Nueva de las primeras décadas del siglo Xx en el campo pedagógico musical (Gainza, 2003). Aunque la influencia concreta puede identificarse con bastante posterioridad — décadas de 1940 y 1950 - la iniciativa renovadora de anteponer las necesidades y la personalidad del educando ante las características del objeto de conocimiento provoca que el niño sea considerado como un sujeto musical, con capacidad expresiva propia, y correr el foco de la música como "objeto" que debe ser enseñado, según las pautas del normalismo. Es en la sutileza de este cambio hallado por la autora, que encontramos una de las principales claves para explicar las transformaciones en la concepción de "lo musical" en la experiencia Cossettini.

\footnotetext{
${ }^{1}$ La escuela nueva, escuela activa o escolanovismo se desarrolló en Argentina como un conglomerado de actitudes, doctrinas e intereses, muchas veces contrapuestos, aunque con un denominador común: la aguda crítica respecto a la pedagogía tradicional, así como también el privilegio otorgado al infante como sujeto — no objeto, tabla rasa— del aprendizaje. Movimiento que comenzó a desarrollarse en la bisagra de los siglos XIX y XX, pero cuya mayor densidad gravitó en la entreguerras. Para abordar la complejidad del escolanovismo argentino se recomienda la lectura, entre otros, de Pineau (2010), Carli (2003), Caruso (2001), Puiggrós (1997), Dussel (1999), Menin (1998).

2 "Escuela Serena" es el apelativo que la educadora Olga Cossettini le impone a su experiencia escolanovista desarrollada en la escuela primaria pública Gabriel Carrasco, dependiente del Ministerio de Instrucción Pública y Fomento de la Provincia de Santa Fe, en Argentina. Tal como Menin señala (1998: 160-161) es un movimiento renovador de la escuela, iniciado en Europa a fines del siglo XIX, fortalecido a principios del XX. Se fue transformando con el tiempo y aparece en América Latina con su impronta renovadora bajo diversos registros, tanto políticos como epistemológicos.

${ }^{3}$ Los vastos materiales reunidos en el Archivo Cossettini (AC), dependiente del IRICE-Conicet incluyen cartas, esquelas, planes, cuadernos, fotografías, registros audiovisuales.
} 
Sin embargo, no podemos ignorar que para las docentes de la Escuela Nueva en general la educación musical estaba presente, pero como actividad marginal, relegada muchas veces a un pasatiempo funcional para que los aprendizajes "importantes" se realizaran de modo óptimo (Jorquera Jaramillo, 2004: 15). De esta manera, al transportar estos posicionamientos a un caso particular como el de la escuela Carrasco, podemos asumir que el concepto de "lo musical" no era el mismo que en otras experiencias escolanovistas, y menos aún que en el resto de las escuelas ligadas al ideario normalista.

Así, si bien escolanovista, la experiencia de las hermanas Cossettini mostraba una inusitada intensidad en la presencia de la música como marco y eje escolar; y se convertía por aquellos años en una instancia caracterizadora de esta propuesta educativa. La música era prácticamente un elemento omnipresente y un referente sustancial de transformación escolar. De allí entonces que la meta de este artículo sea destacar la singularidad y trascendencia de la experiencia Cossettini en relación con la enseñanza y difusión musical, en un marco donde las múltiples expresiones y manifestaciones artísticas estaban presentes en los lineamientos discursivos y prácticos de la propuesta de las pedagogas santafesinas. ${ }^{4}$

Dentro de este contexto donde lo artístico era considerado un elemento central del hecho educativo, esta investigación inicial hace hincapié en dos grandes temas: la gran preocupación de las hermanas Cossettini por incorporar la música como elemento central de su propuesta curricular a través de sus Conciertos fonoeléctricos y las Misiones Culturales, y el diálogo internacional con referentes del mundo de la educación musical para transformar la enseñanza, y difundir e intercambiar resultados.

\section{La práctica pedagógica de Olga Cossettini y la educación estética}

Olga Cossettini fue formada en la escuela normal argentina de principios del siglo xx. Nacida en San Jorge, provincia de Santa Fe, de padres italianos, se recibió de maestra en la Escuela Normal de Coronda, una localidad cercana a la capital de la provincia. Su derrotero como maestra la llevó a recorrer en noroeste regional y tomar conocimiento, desde su praxis, de la educación rural; sin embargo, es su paso por la Escuela Normal Domingo de Oro, de la ciudad de Rafaela, el que marcó su proyección profesional. Bajo la supervisión de Amanda Arias llegó a ser directora del Departamento de Aplicación, cargo que le permitió materializar el mandato Lombardo Radice. Parafraseando el título del libro publicado en

\footnotetext{
${ }^{4}$ La enseñanza por y a través del arte se resaltaba en todas las estrategias desplegadas por las hermanas Cossettini. La pintura, el teatro, la literatura, la escultura, la música estaban siempre presenten en la perspectiva educativa desarrollada por en la escuela Carrasco bajo la dirección de Olga.
} 
1935 por la Universidad Nacional del Litoral, ${ }^{5}$ Olga dirigió en Rafaela uno de los primeros ensayos de su Escuela Serena en la provincia de Santa Fe. Inspirada en la filosofía y en la didáctica italiana diseñada por Gentile y Radice, Olga insistía en que era menester renovar la cultura escolar, y superar las huellas que el positivismo había impuesto en la dinámica educativa y en la formación de los maestros. Una vez discutidos y resignificados esos principios, el ambiente escolar estaría preparado para proyectar nuevas formas de enseñar y de aprender. De este modo, Olga y su equipo de maestras generaron un espacio de enseñanza donde se exaltaba la creatividad de los niños y donde todas las manifestaciones del arte, del juego y de la recreación pudieran hacerse presentes. La meta no era confrontar deliberadamente los programas oficiales, sino superarlos, al atender principalmente la especificidad del niño y no tanto el saber del maestro o la lógica de los contenidos que se iban a transmitir (Fernández y Caldo, 2013: 55). El éxito de la experiencia puso a Olga en el centro de atención del mundo pedagógico nacional, y fue una de las causas para que, en 1935, fuera designada directora de la escuela Carrasco de la ciudad de Rosario. En noviembre del mismo año, el Ministerio de Instrucción Pública y Fomento de Santa Fe le otorgó a esta escuela, dirigida por Cossettini, el carácter de experimental, y aseguró así una importante autonomía para la gestión escolar.

Concretamente, en esta línea de trabajo la intención era alcanzar a los niños y niñas un corpus de saberes que mixturaba los contenidos del currículum oficial con altas dosis de expresiones estéticas: música, canto, pintura, poesía. Manifestaciones que desembarcaban en la escuela por la mediación de los docentes, pero también de la mano de los propios artistas e intelectuales hacedores. Por aquellas aulas, inflamadas de cultura letrada y del gusto estético hegemónico, pasaron escritores, pintores, titiriteros, músicos, que retrabajaron el currículum oficial al calor de sus aportes estéticos. Estas prácticas, alejadas de la cultura escolar dominante, abrían una perspectiva de contacto con los hacedores de cultura para docentes y estudiantes. En la escuela de la "señorita Olga" se enseñaba, mediante el trabajo fuera de las aulas, el diálogo permanente entre el barrio y la escuela, el empleo del arte como recurso didáctico - la música, la pintura y la literatura—, la visita recurrente de artistas y escritores —Gabriela Mistral, Fernando Birri, Juan Ramón Jiménez, Javier Villafañe, Alfonsina Storni, Juan Ramón Jiménez-y, fundamentalmente, la apuesta a que los niños realizaran sus propias obras de arte: dibujos, música, poemas, artesanías, témperas y acuarelas (Fernández y Caldo 2013: 65-66).

Ya desde sus reflexiones pedagógicas, Olga deja entrever claramente que la música era uno de los pilares fundamentales de la educación estética y, por ende, de la educación integral que

\footnotetext{
${ }^{5}$ Referimos al libro Cossettini, Olga (1940), Escuela Serena. Apuntes de una maestra.
} 
perseguían para sus alumnos. En un breve artículo titulado "La estética en la escuela" y publicado en Qvid novi? Suplemento, ${ }^{6}$ señala:

La educación estética contribuye en parte a serenar su espíritu, a aclarar su penumbra, a borrar la arruga precoz que imprimió un prematuro dolor.

Los claros dibujos que animan sus trabajos, las dulces canciones, la danza y el juego que crean el ritmo, las músicas con las que alegran sus paseos, los libros serenos, poesía fresca, ciencia amena, dan a la infancia savia de crecimiento, sin turbarla, sin ajarla ayudándola a crecer niño. (Cossettini, 1939: 5).

Es decir, para la educadora, la música es un estímulo sensorial vital para despertar en los alumnos emociones estéticas que no sólo volvieran más ameno el proceso de aprendizaje, sino que, en paralelo, permitieran aflorar la expresividad innata de todo niño, y los ayudaran a desarrollar una sensibilidad especial frente a lo bello, ya sea en la naturaleza que los rodea, ya sea frente al arte.

Olga amplía esta idea en las siguientes líneas y explica cómo de ello deriva una experiencia habitual en su escuela, como la de los Conciertos fonoeléctricos:

Los niños gustan de la armonía de los sonidos de la naturaleza, antes que los de la música; el gorjeo de los pájaros, la canción del viento, el rumor del agua [...] le producen deleite y este placer se mantiene vivo hasta más allá de su primera infancia. (Cossettini, 1939: 7).

La música de matriz académica era escuchada en las aulas y en el patio escolar. Su uso tenía como meta el estímulo y el acompañamiento de actividades, pero también era un mecanismo para introducir a los estudiantes en el conocimiento de los músicos considerados fundamentales en el arco de la cultura occidental. La reproducción de las obras mediante medios técnicos introducía un recurso novedoso para la escuela argentina, y pone de manifiesto uno de los mandatos del normalismo: la formación del magisterio en la cultura occidental.

La difusión del ideario escolanovista hizo que el intercambio epistolar entre maestros y maestras fuera intenso, en especial para dialogar sobre experiencias, bibliografía y actividades

${ }^{6}$ En este pequeño escrito - que no fue incluido en las Obras Completas editadas por Amsafe en 2001- encontramos la que fuera quizás la primer sistematización del pensamiento de Olga, en la que se ocupa concretamente de la enseñanza de la música en el contexto de la educación estética. Véase Cossettini (1939), "La estética en la escuela". Aunque se desconoce su fecha de publicación exacta, Fernández, Welti, Biselli y Guida, están de acuerdo en datar el material dentro de la década de 1930, ya que la Revista Quid novi? Suplemento era publicada por la Asociación de padres y ex alumnas de la Escuela Normal núm. 2, J. M. Gutiérrez, de Rosario, y esta institución estuvo bajo la dirección de Dolores Dabat, colega y amiga de Olga, introductora de innovaciones decrolyanas en dicho establecimiento, entre 1924 y 1940. Véase Fernández, Welti, Biselli, y Guida (2014). 
tendientes a la difusión y divulgación. En una serie de informes realizado por docentes de la localidad de Bell Ville, provincia de Córdoba, luego de una visita a la escuela experimental, puede leerse: "Una música alegre llena el patio, es el momento que las tareas pueden ser interrumpidas si se desea, es el recreo"? Estas pocas líneas bastan para definir con claridad otro de los roles que cumplía la música en esta escuela: la de delimitar los tiempos escolares. En vez del estridente sonido de la campana utilizado usualmente por las instituciones escolares de la época para indicar taxativamente el comienzo o el fin de las actividades, las hermanas Cossettini preferían inundar el patio con melodías y sonidos apacibles que favorecieran el momento de dispersión de sus alumnos. Del mismo modo, si "lo musical" acompañaba las actividades más lúdicas de los alumnos, como el teatro de títeres, las dramatizaciones y los juegos, no es de extrañar que los niños desarrollaran entonces una relación especial con la música, que fueran mucho más sensibles a ella, que aprendieran a apreciarla y, consecuentemente, que afianzaran a través de la experiencia musical un vínculo de pertenencia con la institución escolar; en definitiva y en palabras de una de las alumnas: "La música nos enseñaba a querer con intenso amor a la escuela y aferrarnos a ella".

Asimismo, Olga afirmaba que de esa forma, haciéndolos escuchar melodías "casi naturales", los niños entraban a los once años en el mundo de la música sintiéndose sus dueños, y eran capaces de elegir por ellos mismos las grabaciones que querían escuchar, hecho que ayuda a las maestras escolanovistas al momento de tener que escoger entre las obras que sean más afines al gusto infantil. Con gran satisfacción podían comprobar la emoción que la música despertaba en sus alumnos cuando "después de escuchar 'Marcha Turca' de Mozart, 'Canción de Primavera' de Mendelssohn, 'Madrigales' de Byr, 'Vidalita' de Massa, etc., un aplauso largo y apretado se agita en el aire acompañado de un reclamo general: bis, bis... otra vez!" (Cossettini, 1939: 8-9).

La música, de este modo, funcionaba como acompañamiento, disparaba estímulos estéticos en los alumnos y mejoraba el clima escolar. Pintar, escribir, modelar, durante o después de la escucha musical era un aspecto buscado y deseado por las maestras para sus estudiantes. La experiencia fue más allá al incorporar a las aulas de la escuela Carrasco la praxis musical; sin embargo, este dato, de un fuerte sentido común, se asentaba sobre una base más sólida que la simple proyección escolanovista. La matriz espiritualista de la formación de esta corriente tenía una carga importante de aportes derivados del idealismo. Tal como afirma Bonds (2014: 53), el idealismo da prioridad al espíritu sobre la materia. Sin rechazar necesariamente el mundo fenoménico, postula la existencia de una forma más elevada de

\footnotetext{
${ }^{7}$ AC. Epistolario. Informe de Margarita H. Boetsch sobre su visita a la escuela experimental Gabriel Carrasco, 27 de junio de 1942. A su vez, esta descripción se ve reafirmada si consideramos también los testimonios de ex alumnos que se exponen en el documental La escuela de la señorita Olga (1991), de Mario Piazza, también resguardado en el AC.

${ }^{8}$ AC Epistolario. Recuerdo de la Escuela Carrasco de Letizia Esther Mujica, sexto grado A, 1950.
} 
realidad en un reino espiritual. Así, el arte y el mundo son armoniosos entre sí desde un punto de vista estético. Tal idea transforma el mundo de las composiciones, pero sobre todo las del propio acto de escucharlas: "Kant había proporcionado la base filosófica que concedía al espectador de cualquier obra de arte, incluida la musical, un papel creativo" (Bonds, 2014: 43).

Es posible suponer que las lecturas espiritualistas de estas maestras, evidenciadas en los propios escritos de Olga Cossettini, permitían superar el marco de referencia habitual de la enseñanza de la música. Las transformaciones devenidas durante todo el siglo xIx y comienzos del Xx, alrededor de las interpretaciones sobre lo que significaba escuchar música, de alguna manera impregnaron las estrategias implementadas por la Escuela Serena.

En el aula y respecto al espacio curricular destinado específicamente a la música como asignatura, Olga sostiene que en su escuela se recurría, como primera medida, al solfeo intuitivo de las hermanas Agazzi. ${ }^{9}$ Este método, si bien no se aleja de la técnica del solfeo tradicional, enseña con materiales didácticos que resultan familiares y accesibles para los niños - escaleritas de papel, por ejemplo-y con el uso de frases sencillas que reemplazaban los nombres de las notas; sin embargo, además de este tipo de ejercitaciones, Cossettini aclara que para completar el método didáctico debe recurrirse a la utilización de instrumentos sencillos, como tambores, triángulos, panderos, timbres y platillos, a fin de organizar desde preescolar una pequeña orquesta acompañada por el piano.

Asimismo, la enseñanza musical en la experiencia de la escuela Carrasco se articulaba con el marco general de la educación artística, la expresión corporal. Por ello, además de su uso como disparador para las actividades plásticas, y a partir de la influencia de los principios de la danza moderna de Laban, M. Morris, M. Wigman y Delacroze, la música se aplicaba a ejercicios de gimnasia rítmica, muchas veces asociados a juegos y rondas populares (Cossettini, 1939: 10-12).

Ahora bien, experiencias como la de la Escuela Serena se esforzaban por instalar en las aulas innovaciones didácticas sobre los usos de la música en el ambiente escolar. La educación musical en Argentina no disponía de una formación disciplinar específica, nutrida en la vasta producción escrita europea, en especial alemana y austrohúngara. La rigurosidad en la apropiación del lenguaje musical, y su transferencia tanto desde la perspectiva de la composición, la ejecución, y la escucha era aún un espacio en ciernes.

Las hermanas Cossettini exploraron un nuevo contexto para acompañar su pedagogía. El perfil musical de su experiencia fue incluido en dos estrategias didácticas que apuntaban a un mismo resultado: mejorar el aprendizaje infantil a través del arte. Los Conciertos fonoeléc-

${ }^{9}$ Las pedagogas italianas Rosa y Carolina Agazzi, al priorizar lo estético, y la espontaneidad infantil en el hecho educativo, sistematizaron una serie de prácticas dentro de la que se destacó la destinada a la enseñanza de la música. Una aproximación puede consultarse en Santamaría Herranz (2006). 
tricos y el Coro de Pájaros presentes sobre todo en las Misiones Culturales, fueron los diseños elegidos por las educadoras. En el marco de estas misiones, los estudiantes salían a la calle, a la plaza, visitaban otras escuelas o instituciones en general llevando consigo los trabajos elaborados durante el año. Esas misiones se realizaron entre 1936 y 1941, preferentemente en noviembre, como corolario del ciclo lectivo. El sentido de estas prácticas, lejos de ser una labor conjunta entre escuela y sociedad, apuntaba a mostrar en el medio lo que se producía en las aulas, con el fin de incorporar a los espectadores a la praxis escolar.

\section{La música en la Escuela de la señorita Olga}

Los Conciertos fonoeléctricos tenían una duración de media hora e incluían la audición de cuatro obras, las cuales eran precedidas por la explicación comentada de los datos biográficos de los compositores, la contextualización de la obra y la explicación del argumento si era pertinente:

Nosotros hemos comprobado, por ejemplo, en los conciertos fonoeléctricos que semanalmente les trasmitimos, que los niños en general prefieren música de carácter imitativo, siguiéndole las canciones maternales y las danzas, repitiéndose de manera subjetiva el mismo proceso objetivo y fisiológico. (Cossettini, 1939: 7).

A su entender y desde sus experiencias, las hermanas Cossettini consideraban muy importante la ubicación espacial y temporal de autores y obras, junto con una breve explicación del argumento de la composición, ya que "de esta manera les resulta [a los niños] más fácil comprender y más grato escuchar"; incluso los hallaba mejor predispuestos a géneros musicales nuevos (Cossettini, 1939: 8-9).

En el mismo sentido, la descripción de los conciertos, titulados por las maestras de la escuela Carrasco como fonoélectricos, se repite y se amplía en El niño y su expresión $n^{10}$ (1940). En este libro, que condensa gran parte de los frutos de su experiencia pedagógica en la escuela Carrasco, su autora agrega obras de otros compositores célebres, como Mendelssohn, Brahms, Mozart, Beethoven, Debussy, Schubert, Schumann, Dvorak, Falla, Strawinsky, así como también la de músicos locales, como Boero, Massa, Ginastera, Aguirre, Gómez Carrillo, entre otros, que también solían ser escuchadas durante estos conciertos; destacada mención merecen además los villancicos, romances y danzas de la Antología Sonora de Curt Sachs (Cossettini, 2001: 214).

${ }^{10}$ El niño y su expresión es el libro que condensa la experiencia de la muestra del mismo nombre desarrollada en el Museo Municipal de Bellas Artes J. B. Castagnino, de la ciudad de Rosario. 
La reproducción de las obras con medios técnicos introdujo un recurso novedoso a la escuela argentina, y habla también de la disposición de material discográfico de las educadoras, que así se convertían en seleccionadoras y mediadoras de los materiales auditivos.

La apropiación de esos "momentos musicales", registrada no sólo en los escritos de Olga, sino también en las notas y cartas de los estudiantes, hizo posible que los estudiantes pasaran con cierta naturalidad y entusiasmo a asumir la tarea de organizar ellos mismos tales conciertos.

Al dar cuenta de ello, como un aspecto más de la capacidad creadora infantil, Olga transcribe en el libro citado los comentarios de Lucinda Suárez, de 14 años, que junto con sus compañeros de sexto curso planificaron cuidadosamente una de dichas audiciones, para lo que escogieron cada pieza e investigaron acerca de sus autores para realizar los comentarios previos ante el resto del alumnado:

Desde hace tres años venimos escuchando concierto fonoeléctricos de música selecta. La señorita Olga nos ha enseñado así a escuchar, comprender y sentir la música. Sus comentarios previos sobre las composiciones que íbamos a escuchar, y sobre autores de renombre nos han hecho amar verdaderamente la música. [...]

El concierto que hoy hemos preparado no es más que una bendición de su siembra.

Con cuánta alegría, con cuánto interés trabajábamos con la señorita Leticia en la preparación de este programa y en la investigación de los comentarios con que íbamos a ilustrar cada una de las composiciones del concierto. (Cossettini, 2001: 219).

La creatividad escolar no concluía allí. Cuando las audiciones terminaban, las docentes pedían a sus alumnos que expresaran su opinión sobre lo escuchado a partir de algún dibujo, obra plástica o composición escrita. Para ejemplificarlo Olga incluye en El niño y su expresión varias composiciones escritas por sus alumnos en las que hacen referencia directa a determinada obra musical escuchada en estos conciertos. En dichas composiciones podemos observar tanto las elocuentes expresiones con las que describen las emociones e imágenes que la música les ha generado, como la apropiación del carácter y el argumento original que los distintos compositores le han dado a sus obras (Cossettini, 2001: 215-218). Asimismo, cuando revisamos su epistolario encontramos respuestas como la de Jorge Romero Brest," en la que comenta: "Recibí los dibujos e impresiones de los niños sobre la audición Debussy. Los he mirado con regalo y los he mostrado a mucha gente". ${ }^{12}$

Podemos percibir así un nuevo rol de "lo musical" que corresponde al de convertirse en un estímulo para que el niño exteriorice su espíritu creador, concretizado en una obra original

11 Jorge Romero Brest fue prestigioso e influyente crítico de arte; marcaría el escenario argentino hasta la década de 1970

${ }^{12}$ AC Epistolario. Carta de J. Romero Brest a Olga Cossettini, 1 de septiembre de 1940. 
y propia que, a criterio de los corresponsales de la docente, demostraba gran calidad artística. Tras superar la idea del formalismo del arte por arte mismo, las Cossettini utilizaban la matriz de la música como "lenguaje de las emociones" y como un vehículo para llegar al oyente, en este caso los niños y niñas de la escuela Carrasco. ${ }^{13}$

Respecto de la segunda estrategia, el Coro de Pájaros, las fuentes muestran que surgió casi de "forma natural y por estímulo de la naturaleza". En esta ocasión, la artífice de tales prácticas fue Leticia Cossettini, cuya sensibilidad e intuición la llevaron a descubrir la nueva faceta creadora de sus alumnos que despertaría celebrados elogios de reconocidos representantes culturales de la época, como Juan Ramón Jiménez y Gabriela Mistral.

En su trabajo Del juego al arte infantil, la hermana de Olga nos ofrece su propia versión, donde explica cómo el coro nació del juego, una mañana de 1936. Leticia solía ocuparse de un grupo de niños, de entre 8 y 10 años, particularmente inquietos, con los que necesitaba con frecuencia salir al aire libre y conversar un rato para serenarlos antes de pretender trabajar con ellos. A raíz de un cuento narrado en una de esas ocasiones, a la maestra se le ocurrió preguntarles “¿Quién sabe imitar el canto de algún pájaro?” (Cossettini, 2001b: 614). En respuesta a su pregunta, Leticia recuerda cómo apareció primero la voz de una paloma delicada y luego la de otra, un tanto trémula y desafinada, pero que pronto logró dar con la nota justa. A este dúo siguieron luego las voces de gorriones, quienes también, poco a poco, fueron acomodando su canto. Estos fueron los primeros pasos de una orquesta de músicospájaros, en el intento de templar sus instrumentos y afinar en la clave correcta; del mismo modo, Leticia tuvo que aprender con ellos a ser su directora orquestal.

Empezamos a entendernos. Mi cara y mis manos fueron antenas de transmisión. Bastaba un leve gesto para saber que ahí, en ese minuto, debía entrar el instrumento (fuese voz de paloma, gorrión, canario o zorzal).

Yo pulsaba la calidad de los sonidos, los enhebraba, ordenaba la música, la marcaba con un signo: alto, grave, agudo, breve, rápido, sostenido, suave... (Cossettini, 2001b: 614).

[...] Debían sentir cierto encanto porque les gustaba ser pájaro e instrumento. Año tras año aparecieron nuevos imitadores. Hubo que agruparlos por espacio, así como se agrupan los instrumentos de una orquesta.

Estaban los instrumentos de esmerados gorgojeos: calandrias, zorzales y canarios.

Los instrumentos estridentes: pirinchos, horneros, benteveos

Los metálicos, como los tordos y los congos.

Los instrumentos de voces breves: tacuaritas, corbatitas y mixtos

Los de tono bajo: el paraguayo y el carpecho.

${ }^{13}$ Bonds (2014: 260-261) señala que esta perspectiva surgida con la llustración y que siguió floreciendo durante buena parte del siglo XIX y las primeras tres décadas del Xx, tuvo dos momentos de inflexión. el primero a mediados del siglo XIX, y el segundo después de la Segunda Guerra Mundial. 
Los de tono menos expresivo, como gorriones y cachilos. Los instrumentos sedosos como las tórtolas. (Cossettini, 2001b: 614-615).

La organización por timbres y alturas quedó establecida y los alumnos incorporaron rápidamente y con gran sensibilidad esos matices. Tan es así que pronto fue necesario dar lugar a nuevos aspirantes que pretendían ser músicos-pájaros, y la selección estuvo a cargo de un jurado compuesto por los mejores imitadores que ya formaban parte del coro (Cossettini, 2001b: 615).

Puede creerse, sin embargo, que una orquesta con voces de aves tenía un repertorio limitado o pocas oportunidades para lucirse ante el público, pero no fue así. Las hermanas Cossettini supieron cómo capitalizar esta experiencia y convertirla en uno de los emblemas culturales de su experiencia pedagógica. Sus apariciones fueron, por lo tanto, bastante frecuentes:

[...el coro] comienza a actuar toda vez que el teatro infantil necesita animar una fronda o traer la sugestión del campo.

Y el coro se depura, crece, se afina. Va a las escuelas de barrios más apartados, actúa por radio, llega al Museo de Bellas Artes, viaja a las ciudades vecinas. (Cossettini, 2001c: 534).

Las líneas de trabajo y reflexión de ambas hermanas marcarían así un nuevo rumbo en la educación musical dentro del espacio de la escuela pública santafesina del periodo, huellas que aún hoy son recordadas por su carácter innovador y heterodoxo.

\section{Los aportes e intercambios para la enseñanza de la música en la experiencia Cossettini}

Durante los años que la escuela dirigida por Cossettini tuvo la condición de experimental, Olga y su equipo desplegaron distintas estrategias para afinar las formas de incorporación de la música al espectro de enseñanza. El esfuerzo significó una exploración de bibliografía que permitiera sustentar las variables aplicativas de la música en la escuela. Olga no dudó en buscar los referentes del momento en la enseñanza musical. El intercambio epistolar fortaleció el uso de los textos, y tuvo además un efecto secundario muy importante para la imagen profesional de Olga. Tempranamente, Cossettini intercambió los resultados de su experiencia con pedagogos, funcionarios, artistas y académicos; con ellos se abocó a fortalecer esos lazos de sociabilidad intelectual que hicieron posible, en los primeros años de la década de 1940, su viaje a Estados Unidos al ganar, en virtud de su trayectoria, la Beca 
Guggenheim. ${ }^{14}$ Un porcentaje interesante de tales lazos tuvo como punto de partida o involucró la experiencia de la enseñanza de la música en la escuela. El intercambio epistolar con Curt Sachs, prestigioso musicólogo alemán, exiliado en Estados Unidos, representa el mejor ejemplo de la preocupación de Olga por inquirir, reflexionar y poner en cuestión el tema de la música en la escuela.

El uso de la Antología de Instrumentos Musicales, de Curt Sachs, docente de la New York University, había generado mucha expectativa en Olga. En sucesivas misivas que envía luego de la publicación del libro El niño y su expresión se evidencia el contacto y el intercambio propuesto:

\begin{abstract}
Me hace muchísimo gusto mirar su libro tan hermoso con los trabajos admirables de sus alumnos... Yo, de mi parte soy orgulloso de que mi Antología Sonora ocupa un puesto en el plan de enseñanza de su colegio. Le agradezco de todo corazón por haberme mandado este libro. Con profunda admiración le saludo atentamente..15
\end{abstract}

El libro, como tarjeta de presentación, fortalece redes que iban más allá de lo meramente institucional y reactiva lazos que se habían generado con anterioridad. Curt Sachs, quien había trascendido en el mundo de la música por sus escritos, en especial su Enciclopedia de Instrumentos Musicales, y por su posición de hacer accesible al gran público la enseñanza de la música, era un singular ejemplo de la dedicación de Olga y Leticia por nutrirse de influencias de primer nivel académico, pero también, tal como dicen Fernández y Caldo (2013), por la búsqueda de relaciones que tuvieran como caja de resonancia Latinoamérica y Estados Unidos, en pos de consolidar un perfil panamericanista que se prolongaría más exitosamente durante las décadas siguientes. Así, cuando en junio de 1941 Olga recibe el beneplácito de L. S. Rowe, director general de la Unión Panamericana, por haber tenido "el alto honor" de su nombramiento a una de las becas Guggenheim, ${ }^{16}$ se organizaría rápidamente una nutrida agenda para la becaria argentina.

En septiembre, Olga se embarca rumbo a Estados Unidos; llega en octubre, momento en el cual comienza a recibir numerosísimas misivas que muestran la activa sociabilidad

\footnotetext{
${ }^{14}$ Olga Cossettini gana la beca Guggenheim en la convocatoria de 1941. En septiembre de 1942 se embarca rumbo a Nueva York, adonde llega en octubre. La beca Guggenheim significaba un importante reconocimiento económico para la formación de académicos. Si bien comenzó a otorgarse en 1925 sólo de forma nacional, poco a poco fue incorporando en sus convocatorias a otros países, y a Argentina en particular en 1929. El objetivo de esta beca era intercambiar saberes permaneciendo las personas seleccionadas entre seis meses y un año en Estados Unidos. Olga, durante su estancia, recorre varias escuelas e instituciones; entre sus intereses estaba la enseñanza artística en las escuelas estadounidenses (Fernández, 2014: 18)

${ }^{15}$ AC, caja 342, Carta de Curt Sachs, New York University, Nueva York, 16 de noviembre de 1940.

${ }^{16}$ AC, Epistolario, Carta de L. S. Rowe, Director General, a Olga Cossettini, Pan American Union, Washington, 26 de junio de 1941.
} 
desplegada por la pedagoga desde su domicilio de Riverside Drive, en Nueva York. Antes de finalizar el mes, F. J. Rey, de la Lincoln School, le envía una sugerente nota que expone lo que sería una constante en el periplo de Cossettini:

Estoy enamorado de la belleza y de la cualidad espiritual de su libro [...] No recuerdo descripciones más originales, más profundas, y más hermosas que estas, en la página 36, sobre el "Claro de Luna" de Beethoven. Deseo mucho verla otra vez para presentarla a la doctora Coleman. ${ }^{17}$

Nuevamente, la experiencia de Cossettini en el uso de la música para la enseñanza trasciende las fronteras de la escuela Carrasco y de Argentina. Cuando el libro no es su tarjeta de presentación se articulan otros lazos que le permiten ingresar al mundo universitario y educativo. Por ejemplo, M. Elizabeth Barry le escribe al Dr. Roma Gans, del Teachers College de la Universidad de Columbia, para que reciba y acerque a la maestra argentina a la problemática de las progressive schools, ${ }^{18}$ donde además se resalta el uso de la música para las instancias áulicas.

Por su parte, F. J. Rex, de la Lincoln School of Teachers College, a partir de la lectura de El niño y su expresión invita varias veces a Olga para que se interiorice con el cuerpo docente, en particular con la Sra. Coleman, de cómo se estaba desarrollando la tarea de la enseñanza musical en la institución por él dirigida. Insiste Rex en que se intercambien idearios y praxis sobre la "música creadora" en los niños, y en tal sentido prepara una audición para Olga de una sinfonía escrita y ejecutada por los niños. ${ }^{19}$

La gran expectativa que la visita de Olga generó en el mundo pedagógico estadounidense se debía a la eficiente divulgación de El niño y su expresión en ese país. ${ }^{20}$ Ya en abril de 1942, María Hoge, directora de la Oficina de Relaciones Interamericanas de la Universidad de Stanford, solicitaba la colaboración y consulta de Olga para el plan educativo que deseaban llevar adelante en las escuelas del estado, y resaltaba en especial el intercambio de las experiencias de los niños estadounidenses y latinoamericanos. Las metas de fomentar el

\footnotetext{
${ }^{17}$ AC, Epistolario, Carta de F. J. Rex a Olga Cossettini, Lincoln School of Teachers College, Nueva York, 24 de octubre de 1941.

${ }^{18}$ AC, Epistolario, Carta de M. Elizabeth Barry a Roma Gans, Teacher College, Columbia University, Nueva York, 17 de octubre de 1941.

${ }^{19}$ AC, Epistolario, Carta de J. F. Rex a Olga Cossettini, Teacher College, Lincoln School, Nueva York, 24 de octubre de 1942

20 Véase específicamente sobre la difusión del libro El niño y su expresión los textos de Fernández y Caldo (2013: 97-118) y de Fernández (2014).
} 
estudio de la vida en toda América a través de la correspondencia entre los alumnos, insistía en uno de sus apartados en la cuestión de la dinámica de lo musical en el aula y fuera de ella. ${ }^{21}$

Entre todos los corresponsales con los que Olga -y en algunos casos también Leticia - ha mantenido contactos epistolares hallamos además varios personajes que han dedicado su vida a la música y en particular a que los niños se familiaricen con ella. Tal es el caso de Rubén Carámbula, director de la Escuela Infantil de Iniciación Musical de Montevideo. Carámbula inauguró una muestra en la escuela uruguaya con las acuarelas que Olga y Leticia le habían enviado. El acto, "literario musical", contó con una nutrida presencia de artistas, intelectuales y autoridades escolares, que prestigiaba su labor. En tal sentido, Carámbula no deja de agradecer en su misiva la importancia del aporte de la experiencia "Serena" en la enseñanza de la música en Uruguay. ${ }^{22}$

Así la traza de la sociabilidad propuesta en particular por Olga para difundir su experiencia, pero además para dialogar con el medio académico y escolar argentino y americano, es hito fundamental en la legitimación del proyecto de Escuela Serena, y su proyección durante todo el siglo xx como un referente dentro de la educación pública argentina.

\section{Conclusión}

Steinberg (2008: 17-20) señala que el deseo de aislar los discursos estéticos y lógicos de la ideología durante las décadas de 1930 y 1940, intensificado en la segunda posguerra, llevó a considerar y analizar la música como un modelo matemático, potencialmente menos peligroso que las argumentaciones con base cultural que apostaban a interpretar y contextualizar los fenómenos musicales. ${ }^{23}$ La escisión entre formalistas y contextualistas marcó una tendencia durante la segunda mitad del siglo xx. Los primeros de alguna manera "triunfaron" sobre los segundos, pero la recuperación de las interpretaciones de Theodor Adorno hizo que el contexto de la música se transformara en "fuente de su potencial crítico".

Interpretar la música, contextualizarla en todos sus aspectos, entre ellos los educativos, abre a las puertas a estudios históricos socioculturales, entre los cuales puede referenciarse

\footnotetext{
${ }^{21}$ AC, Epistolario, Carta de María Hoge a Olga Cossettini, Oficina de Relaciones Internacionales, Universidad de Stanford, California, 19 de abril de 1942.

${ }^{22}$ AC, Epistolario, Carta de Rubén Carámbula a Olga Cossettini, Escuela Infantil de Iniciación Musical, Montevideo, 27 de septiembre de 1942

${ }^{23}$ Al ampliar esta argumentación Steinberg (2008: 19) afirma: "el ascenso del formalismo abstracto en la musicología sigue una curva histórica que valdría la pena comparar con el ascenso de la filosofía analítica, en particular de la variante conocida como positivismo lógico, que tuvo su origen en la Viena de los años veinte y luego se abrió paso hacia Inglaterra y Estados Unidos. El positivismo lógico y el musicológico reaccionaron de manera contundente contra las históricamente evidentes (pero no históricamente necesarias) tendencias de las argumentaciones con base cultural a evolucionar hacia programas de excepcionalismo e ideologías culturales".
} 
la experiencia pedagógica desplegada por Olga y Leticia Cossettini. La utilización de la música como referente didáctico, pero también, y más importante aún, como una forma de apropiación artística por los niños y niñas de la escuela Carrasco, es un elemento de singularidad propuesto por la Escuela Serena.

Las hermanas Cossettini utilizaron el efecto musical, como afirma Maconie (2007: 83), como una imagen del mundo del sonido, al igual que la pintura y la escultura del mundo visible. El Coro de Pájaros y las audiciones de los Conciertos fonoeléctricos funcionaron como metáforas del mundo del sonido en la vida real, en el primer caso, y como una comprensión de la percepción auditiva que, al envolver a los estudiantes rosarinos, los empujaba al conocimiento y la sensibilidad artística. Los niños y niñas de la escuela Carrasco no componían obras musicales. La música académica, ejemplo por excelencia del fenómeno artístico, exige un grado de conocimiento superior del lenguaje musical que excedía largamente los conocimientos de los propios docentes encargados de llevar adelante la propuesta.

Un poco de intuición, otro poco de clima de época, buenos aportes bibliográficos, aunados con la formación pedagógica escolanovista, permitieron hacer de la experiencia Cossettini un suceso de excepción. La faceta intuitiva se evidenció en la plasticidad de las docentes para plantear una praxis escolar que trascendía las propias líneas escolanovistas, en lo relativo a la música. El Coro de Pájaros y los resultados obtenidos a partir de los Conciertos fonoeléctricos dan cuenta de ello.

Por otro lado, si bien hablar de clima de época es un tanto vago, los diálogos sobre lo musical, la música académica, la música popular, la transferencia musical, los efectos ideológico-políticos de componer, ejecutar y escuchar música se encontraban en efervescencia en las primeras décadas del siglo XX. ${ }^{24}$ En Argentina también puede rastrearse el efecto de tal dinamismo cultural, que superaba largamente el ámbito escolar, para trasladarse al debate cultural de entreguerras, guerra y segunda posguerra (Gianera, 2011).

Las hermanas insisten también en mantener una profunda interacción con músicos, compositores, musicólogos e historiadores del arte que sostenían en sus textos, visitas y composiciones, la estrategia didáctica desplegada que estaba acompañada por el esfuerzo constante para incorporar los aportes más novedosos del escolanovismo en materia de enseñanza musical.

Estos temas, sumados al profundo compromiso de Olga y Leticia con la enseñanza creativa a partir del uso de la música como pilar de su modelo educativo, hicieron posible dotar de singularidad la experiencia de la Escuela Serena, y colocarla como un referente novedoso y temprano en el mundo pedagógico argentino y americano.

\footnotetext{
${ }^{24}$ Misha Aster (2009) analiza en su texto la contradictoria combinación entre valoración estética, principios ideológicos y gustos personales.
} 


\section{Fuentes}

Aster, Misha (2009), La orquesta del Reich. La filarmónica de Berlín y el nacional socialismo, Edhasa, Barcelona.

Bonds, Marc Evan (2014), La música como pensamiento, Acantilado, Barcelona.

Carli, Sandra (2003), Niñez, pedagogía y política. Transformaciones de los discursos acerca de la infancia en la historia de la educación argentina entre 1880 y 1955, Miño y Dávila Editores, Buenos Aires.

Caruso, Marcelo (2001), "¿Una nave sin puerto definitivo? Antecedentes, tendencias e interpretaciones alrededor del movimiento de la Escuela Nueva", en Pablo Pineau, Inés Dussel y Marcelo Caruso, La escuela como máquina de educar. Tres escritos sobre un proyecto de la modernidad, Paidós, Buenos Aires, pp. 93-134.

Dussel, Inés y Marcelo Caruso (1999), La invención del aula. Una genealogía de las formas de enseñar, Santillana, Buenos Aires.

Fernández, Ma. del Carmen, Ma. Elisa Welti, Rubén Biselli y Ma. Eugenia Guida (2014), Olga y Leticia Cossettini en la Escuela Serena. Cultura, Imagen y Pedagogía (Rosario, 1935-1950), Laborde Libros Editor, Rosario.

Fernández, Sandra y Paula Caldo (2013), La Maestra y el Museo: gestión cultural y espacio público 19391942, El Ombú Bonsái, Rosario.

Fernández, Sandra (2014), "Trascender la escuela. La proyección continental de Olga Cossettini, a partir de la experiencia de 'El niño y expresión', en la década de 1940", // Congreso de Historia Intelectual de América Latina, "La biografía colectiva en la historia intelectual latinoamericana", UNQ-CedinciUNSAM, Buenos Aires.

Pineau, Pablo (2010), Historia y política de la educación argentina, Ministerio de Educación de la Nación, Buenos Aires.

Puiggróss, Adriana (dir.) (1997), Historia de la educación en Argentina. La educación en las Provincias y Territorios Nacionales (1885-1945), Galerna, Buenos Aires.

Gainza, Violeta (2003), "La Educación Musical entre dos siglos: del modelo metodológico al nuevo paradigma", Serie Documentos de trabajos Escuela de Educación de la Universidad de San Andrés, Documento núm. 10, USAL, documento pdf, disponible en: <www.udesa.edu.ar/files/ESCEDU/DT/ DT10-GAINZA.PDF>, (consulta: 23/05/2015).

Gianera, Pablo (2011), La música en el grupo Sur. Una modernidad inconclusa, Eterna Cadencia Editora, Buenos Aires.

Joquera Jaramillo, Ma. Cecilia (2004), "Métodos históricos o activos en la educación musical", Revista electrónica de Leeme (Lista Europea de Música en la Educación), núm. 14, documento pdf, disponible en <musica.rediris.es/leeme/revista/jorquera04.pdf> (consulta: 14/06/2915).

Maconie, Robin (2007), La música como concepto, Acantilado, Barcelona.

Santamaría Herranz, Pablo (2006), "Apuntes para un modelo didáctico de la enseñanza del lenguaje musical en la etapa de infantil", Revista Pulso, Escuela Universitaria Cardenal Cisneros, núm. 29, pp. 95-115.

Menin, Ovide (1998), "El ensayo de 'escuela serena' realizado por las hermanas Cossettini en la República Argentina", Revista da Faculdade de Educação, núm. 1, vol. 24, pp. 160-176.

Steinberg, Michael (2008), Escuchar la razón. Cultura subjetividad y la música del siglo XIX, FCE, Buenos Aires. 
Obras de Olga y Leticia Cossettini

Cossettini, Olga, (1939) "La estética en la escuela", Quid Novi? Suplemento, Revista de la Escuela Normal núm. 2, J. M. Gutierrez, tomo VII, núm. 31.

Cosettini, Olga (1940), Escuela Serena. Apuntes de una maestra, Talleres Gráficos Argentinos, Buenos Aires.

Cossettini, Olga (200la), "El niño y su expresión", en Obras completas, Ediciones Amsafe, Santa Fe.

Cossettini, Leticia (2001b), "Del juego al arte infantil", en Obras completas, Ediciones Amsafe, Santa Fe.

Cossettini, Leticia (2001c), "Teatro Infantil", en Obras completas, Ediciones Amsafe, Santa Fe.

Sandra Fernández. Doctora en historia, investigadora Conicet, Universidad Nacional de Rosario, Argentina. Líneas de investigación: historia sociocultural argentina, historia regional. Publicaciones recientes: (2014), "Olga Cossettini en el laberinto de la sociabilidad política santafesina (Argentina, 1937-1943)", Revista Brasileira de Histórica da Educação, Sociedad Brasileira de Histórica da Educação, pp. 190-199, disponible en: <www.rbhe.sbhe.org.br>; (2013), "Sociabilidad, arte y cultura. Una experiencia en la Argentina de entreguerras", História Unisinos, vol. 13, núm. 1, pp. 248-256, disponible en: <revistas.unisinos.br/index.php/ historia>.

Micaela Yunis. Profesora de historia, Universidad Nacional de Rosario, Argentina. Líneas de investigación: historia sociocultural argentina, historia regional. Publicaciones recientes: (2013) "La historia de vida de Jorge Yunis: Una excusa para el análisis del proceso histórico en el interior santafesino entre 1880-1960", Estudios del ISHIR, vol. 3, núm. 7, pp. 120-138, disponible en: <revista.ishir-conicet.gov.ar/ojs/index.php/revistalSHIR>.

Recibido: 22 de septiembre de 2015 Aceptado: 14 de abril de 2016 